\title{
Hospitalizations due to respiratory failure in patients with Amyotrophic Lateral Sclerosis and their impact on survival: a population- based cohort study
}

\author{
Federica Edith Pisa ${ }^{1,3^{*}}$, Giancarlo Logroscino ${ }^{2}$, Paolo Giacomelli Battiston ${ }^{3}$ and Fabio Barbone ${ }^{1,3,4}$
}

\begin{abstract}
Background: Respiratory failure, infections and aspiration pneumonia, are the main causes of morbidity and mortality in Amyotrophic Lateral Sclerosis (ALS). In a population-based cohort, we assessed (a) hospital utilization and (b) impact of hospitalization for respiratory failure on survival.

Methods: All patients with incident ALS in Friuli Venezia Giulia region, Italy, from 2002 to 2009, were identified through multiple sources. Diagnosis was validated through clinical documentation review. For each patient, we extracted the records of all hospitalizations after ALS diagnosis from the regional hospitalization database. Cox proportional hazards model survival Hazard Ratio (HR), with $95 \%$ Confidence Interval (95\% Cl), was calculated.

Results: Out of 262 patients, $98.1 \%$ had at least 1 and $58.0 \% \geq 3$ hospitalizations. Emergency admissions occurred in $77.5 \%$ of patients and a diagnosis of respiratory failure in $55.0 \%$. Patients underwent a total of 885 hospitalizations. The leading diagnosis was respiratory failure (31.6\% of hospitalizations). This diagnosis occurred most frequently in emergency (45.6\%) than in elective admissions (26.4\%). The second leading diagnosis was pneumonia (14.2 \%), 24.9 and $6.3 \%$ respectively. The leading procedure was mechanical ventilation (18.4\%), performed in $29.9 \%$ of emergency and in $12.4 \%$ of elective admissions. After adjustment for site of onset, age and diagnostic delay, a first hospitalization for respiratory failure had a strong adverse effect on survival (HR 4.00; $95 \% \mathrm{Cl} 3.00 ; 5.34)$.

Conclusions: Respiratory failure, pneumonia and aspiration pneumonia were major determinants of hospitalizations and emergency admissions and often dealt with in emergency admissions. A first hospitalization for respiratory failure had a strong adverse effect on survival. Strategies to improve home management of respiratory conditions in patients with ALS and to optimize hospital care utilization are needed.
\end{abstract}

Keywords: Amyotrophic Lateral Sclerosis, Hospital utilization, Hospitalization, Respiratory failure, Non-invasive ventilation, Tracheostomy, Mechanical ventilation, Survival, Cohort studies, Database research

\section{Background}

During the course of disease, patients with Amyotrophic Lateral Sclerosis (ALS) experience a progressive loss of muscular function leading invariably to disability, paralysis and death. In European population-based studies, median survival time was between 25 and 30 months

\footnotetext{
* Correspondence: federica.pisa@uniud.it

${ }^{1}$ Institute of Hygiene and Clinical Epidemiology, University Hospital of Udine, Via Colugna 50, Udine 33100, Italy

${ }^{3}$ Department of Biological and Medical Sciences, University of Udine, Udine, Italy

Full list of author information is available at the end of the article
}

from disease onset [1]. Respiratory failure and complications such as infections and aspiration pneumonia are the main causes of morbidity and mortality. Respiratory function is strongly related to ALS outcome [2]. In the early phase of disease, Sniff Nasal Inspiratory Pressure is a strong predictor of death or tracheostomy within 1 year of follow-up [3]. Decreased Forced Vital Capacity due to muscle weakness has been associated with an increased risk of short-term mortality [4]. In patients with early respiratory failure, noninvasive ventilation (NIV) is recommended $[5,6]$. 
NIV prolongs survival and may improve patients' quality of life [7]. Recommendations include advance directives and planning of respiratory failure management to avoid emergency invasive ventilation [5]. Invasive mechanical ventilation can prolong survival but has uncertain impact on the quality of life of patients and caregivers [5, 8]. The prevalence of invasive ventilation varies greatly between countries [9] and within Italy from $10.6 \%$ [10] to $24.5 \%$ [11], as reported by population-based studies.

Hospital care utilization is common in patients with ALS and represents the third main contributor to costs of care, after home care and ventilation [12]. The proportion of patients hospitalized decreased from $80 \%$ in 2000 to less than $40 \%$ in 2012 [13]. Evaluating hospital admissions with a diagnostic code for ALS in large US administrative databases, two studies reported that emergency admissions were common while only about $20 \%$ were elective $[14,15]$. The main reasons for hospitalization were respiratory failure and pneumonia. Patients admitted for respiratory failure showed a 5fold increased risk of dying in hospital (odds ratio of death: 5.03; 95 \% CI 4.57-5.54); in-hospital mortality was $25.4 \%$ in the subgroup undergoing CPAP/BiPAP and $30 \%$ in the subgroup undergoing mechanical ventilation $<96 \mathrm{~h}$ [14].

In other respiratory diseases such as idiopathic pulmonary fibrosis, early and respiratory-related hospital admissions have been associated with increased allcause mortality [16]. In patients with ALS, the effect of hospitalizations for respiratory conditions on overall survival has not been evaluated.

Several studies suggest that the modality of health care provision for patients with ALS has a relevant impact on quality of life and use of healthcare facilities. Patients followed up by multidisciplinary centers had lower in-hospital mortality and shorter length of stay [10]. Community care management and coordination led to a decrease in overall and emergency nonplanned hospitalizations [13]. Telemonitoring of home NIV reduced hospital admissions and emergency room visits [17].

This population-based cohort study of incident ALS cases in Friuli Venezia Giulia (FVG) region, Northeastern Italy, from 2002 to 2009, aims to assess: (a) hospitalizations after the diagnosis of ALS, focusing on admissions and procedures related to respiratory problems and (b) the impact of hospitalizations for respiratory failure on survival.

\section{Methods}

\section{Study population}

The study was conducted in FVG resident population, approximately 1,200,000 inhabitants [18].

\section{Data sources}

All FVG residents are registered with the Regional Health System, providing universal access to care. Their use of health services is registered in computerized databases. Anonymized individual records can be linked by a unique personal identifier. For this study the database of hospitalizations was used. This database records data of all hospitalizations of residents in hospitals of FVG and of other Italian regions. Dayhospital admissions, where the patient was admitted and discharged within $24 \mathrm{~h}$, are also included. For each hospitalization, the following information is registered: dates of admission and discharge, type of admission (emergency, elective or day hospital), one primary and up to five secondary discharge diagnostic codes and up to six codes for procedures, if hospitalization ended with death and date of death. Emergency admissions are those not planned in advance but occurring abruptly due to clinical need.

Diagnoses and procedures are coded according to the International Classification of Diseases, ninth revision, clinical modification (ICD-9-CM) coding system.

\section{Study cohort}

The cohort included any resident with an incident diagnosis of ALS from January 1st, 2002 to December 31, 2009. The ascertainment of cases has been described elsewhere [19]. Multiple sources, including database of hospitalizations, electronic medical records and archives of Neurology departments, were used to detect patients diagnosed during in- or out-patient medical encounters. ALS diagnosis was validated through clinical documentation review. For each detected case, four neurologists independently reviewed clinical documentation for any hospitalization or relevant healthcare encounter up to December 31, 2009, to confirm the diagnosis. ALS confirmation was based on information relative to the entire follow-up and required the following criteria to be met: (a) ALS diagnosis explicitly written by a neurologist and/ or (b) prescription for Riluzole in the therapeutic plan. All patients with confirmed ALS and a diagnosis of possible, probable or definite ALS according to El Escorial criteria $[20,21]$ were included.

\section{Data collection}

Information on date of diagnosis and site of onset was abstracted from clinical documentation. The date of diagnosis was defined as (a) the date of discharge when ALS was diagnosed or confirmed during a hospitalization (the diagnosis was written by the physician on the discharge letter) or (b) the date of the examination, when ALS was diagnosed during an outpatient examination. We extracted the records of all hospitalizations from January 1st, 2000 to December 31, 2011, 
information on residential history (to account for potential emigration from the region) and date of death, up to December 31, 2011.

Hospitalizations after the diagnosis of ALS where those with date of admission after the date of diagnosis. Vital status of patients at the end of follow-up (December 31, 2011) was ascertained through record linkage with the mortality database.

\section{Statistical analysis}

Taking the patient as statistical unit, we performed a descriptive analysis of their characteristics and hospitalizations according to ALS site of onset. Frequencies were compared through the chi square test. Kaplan Mayer product-limit survival function was used to calculate survival times, overall and after the first hospitalization (a) for respiratory failure, both as primary or any secondary code, (b) tracheostomy or (c) mechanical ventilation (MV).

Survival Hazard Ratios (HR), with 95 \% Confidence Interval $(95 \% \mathrm{CI})$, were calculated through Cox proportional hazards model. The following terms were assessed in univariate analysis: having a first hospitalization for respiratory failure after the diagnosis of ALS, type of onset, sex, age at disease onset, diagnostic delay (lag time between the onset of symptoms and diagnosis), Charlson Comorbidity Index and having a hospitalization for respiratory failure before the diagnosis of ALS. The first hospitalization for respiratory failure after the diagnosis of ALS was defined as the first hospitalization after the date of diagnosis with one of the following primary or any secondary ICD-9-CM codes: 518.81 acute respiratory failure, 518.83 chronic respiratory failure, 518.84 acute on chronic respiratory failure and 518.82 unidentified respiratory failure. This variable was time-dependent and was therefore included in the model using the counting process method [22].

A hospitalization for respiratory failure before the diagnosis of ALS was defined as occurred any time before the date of diagnosis with one of the above reported primary or any secondary ICD-9-CM codes.

Taking the hospitalization as the statistical unit, we performed a descriptive analysis of diagnoses and procedures according to the type of admission (emergency, elective or day-hospital).

Statistical analysis was performed using SAS๑ statistical package 9.2 (SAS Institute Inc., Cary, N.C., USA).

\section{Results}

A total of 262 patients, $50.4 \%$ men, $49.6 \%$ aged $\geq 68$ years at diagnosis, were identified (Table 1). The site of onset was spinal in $50.7 \%$ and bulbar in $34.0 \%$. Information on the site of onset was missing in $15.3 \%(N=40)$.
Four patients died during the hospitalization where the diagnosis was made and were excluded from the analysis. Only one patient did not have any hospitalization after the diagnosis, $98.1 \%(N=257)$ were hospitalized at least once after the diagnosis and $58.0 \%$ three or more times. More than $75.0 \%$ had at least one emergency admission and $41.2 \%$ two or more.

More than $50 \%$ were hospitalized at least once for respiratory failure and $45.0 \%$ for acute respiratory failure. Hospitalizations for respiratory failure were more common in patients with bulbar onset (58.4\%), than in those with spinal $(54.9 \%)$ or unknown $(47.5 \%)$ onset $(p=0.02)$. One third of patients underwent MV, more frequently those with spinal onset (40.6\%) than with bulbar $(23.6 \%)$ or unknown onset $(30.0 \%)(p=0.03)$. Overall, $22.9 \%$ underwent tracheostomy, more frequently those with spinal onset $(27.8 \%)$. Only $11.1 \%$ $(N=29)$ underwent in-hospital NIV.

By the end of follow-up, $81.7 \%$ of patients were deceased; $53.3 \%$ of them died in hospital. During followup, the cohort had 885 hospitalizations (Table 2). Emergency admissions accounted for $47.6 \%$. Median length of stay was 8 days (Inter Quartile Range IRQ 4; 15) in elective and 8 days (IQR $4 ; 17$ ) in emergency admissions (data not shown).

Respiratory failure was the most common discharge diagnosis, occurring as primary code in $19.4 \%$ and in any position in $31.6 \%$ hospitalizations, followed by pneumonia (5.5 and $14.2 \%$, respectively) and aspiration pneumonia (1.0 and $2.1 \%$, respectively).

Respiratory failure, acute respiratory failure and pneumonia were more frequent in emergency admissions, occurring as primary and/or secondary code in 45.6, 32.8 and $24.9 \%$ hospitalizations, respectively. Conversely, acute respiratory failure or pneumonia were uncommon in day hospital admissions (each $1.2 \%$ ). Aspiration pneumonia occurred almost exclusively in emergency admissions.

More than $80 \%$ of the 114 patients who died in hospital, died in emergency hospitalizations. In hospitalizations ending with death, respiratory failure $(58.8 \%)$ and diseases of the respiratory system (43.9\%) were the most common codes (Additional file 1: Table S1).

The most common procedure was MV, performed in $18.4 \%$ hospitalizations and more frequently $(13.2 \%)$ lasting $\geq 96 \mathrm{~h}$, followed by tracheostomy (7.1 \%) and NIV (3.9 \%) (Table 3). MV was more common in emergency $(29.9 \%)$ than in elective (12.4 \%) admissions, as well as NIV (5.0 \% vs. $2.0 \%)$ and tracheostomy (12.6 \% vs. $3.3 \%)$. Conversely, gastroor entero-stomies were performed more frequently in elective $(13.0 \%)$ admissions.

Diagnostic procedures, such as electromyography (12.6\%) and magnetic resonance imaging (MRI) (6.8\%), 
Table 1 Number and distribution of patients with ALS by selected characteristics and hospitalizations after the diagnosis of ALS

\begin{tabular}{|c|c|c|c|c|c|c|c|c|c|c|}
\hline & & \multicolumn{6}{|c|}{ Site of onset } & \multirow[t]{3}{*}{$p^{a}$} & \multirow{2}{*}{\multicolumn{2}{|c|}{$\begin{array}{c}\text { TOTAL } \\
(\mathrm{N}=262)\end{array}$}} \\
\hline & & \multicolumn{2}{|c|}{$\begin{array}{l}\text { Bulbar } \\
(\mathrm{N}=89)\end{array}$} & \multicolumn{2}{|c|}{$\begin{array}{c}\text { Spinal } \\
(\mathrm{N}=133)\end{array}$} & \multicolumn{2}{|c|}{$\begin{array}{c}\text { Unknown } \\
(\mathrm{N}=40)\end{array}$} & & & \\
\hline & & $\mathrm{N}$ & $\%$ & $\mathrm{~N}$ & $\%$ & $\mathrm{~N}$ & $\%$ & & $\mathrm{~N}$ & $\%$ \\
\hline \multicolumn{11}{|c|}{ Age at diagnosis } \\
\hline & $<68$ & 38 & 42.7 & 79 & 59.4 & 15 & 37.5 & \multirow[b]{2}{*}{0.01} & 132 & 50.4 \\
\hline & $\geq 68$ & 51 & 57.3 & 54 & 40.6 & 25 & 62.5 & & 130 & 49.6 \\
\hline \multicolumn{11}{|l|}{ Sex } \\
\hline & Men & 36 & 40.4 & 75 & 56.4 & 21 & 52.5 & \multirow{3}{*}{0.06} & 132 & 50.4 \\
\hline & Women & 53 & 59.6 & 58 & 43.6 & 19 & 47.5 & & 130 & 49.6 \\
\hline \multicolumn{10}{|c|}{ Hospitalizations $^{\mathrm{a}}$ (number) } & \\
\hline & 1 & 22 & 24.7 & 24 & 18.0 & 7 & 17.5 & \multirow{4}{*}{0.46} & 53 & 20.2 \\
\hline & 2 & 14 & 15.7 & 27 & 20.3 & 11 & 27.5 & & 52 & 19.8 \\
\hline & $\geq 3$ & 51 & 57.3 & 80 & 60.2 & 21 & 52.5 & & 152 & 58.0 \\
\hline & Subtotal $\geq 1$ & 87 & 97.8 & 131 & 98.5 & 39 & 97.5 & & 257 & 98.1 \\
\hline \multicolumn{11}{|c|}{ Emergency admissions } \\
\hline no & & 19 & 21.3 & 30 & 22.6 & 5 & 12.8 & \multirow{5}{*}{0.44} & 54 & 20.6 \\
\hline yes & 1 & 38 & 42.7 & 41 & 30.8 & 16 & 41.0 & & 95 & 36.3 \\
\hline & 2 & 15 & 16.9 & 33 & 24.8 & 10 & 25.6 & & 58 & 22.1 \\
\hline & $\geq 3$ & 15 & 16.9 & 27 & 20.3 & 8 & 20.5 & & 50 & 19.1 \\
\hline & Subtotal yes & 68 & 76.4 & 101 & 75.9 & 34 & 85.0 & & 203 & 77.5 \\
\hline \multicolumn{11}{|c|}{ Hospitalization for respiratory failure $^{b}$} \\
\hline no & & 35 & 39.3 & 58 & 43.6 & 20 & 50 & \multirow{5}{*}{0.02} & 113 & 43.1 \\
\hline yes & 1 & 37 & 41.6 & 33 & 24.8 & 10 & 25 & & 80 & 30.5 \\
\hline & 2 & 12 & 13.5 & 19 & 14.3 & 6 & 15 & & 37 & 14.1 \\
\hline & $\geq 3$ & 3 & 3.4 & 21 & 15.8 & 3 & 7.5 & & 27 & 10.3 \\
\hline & Subtotal yes ${ }^{\mathrm{d}}$ & 52 & 58.4 & 73 & 54.9 & 19 & 47.5 & & 144 & 55.0 \\
\hline \multicolumn{11}{|c|}{ Hospitalization for acute respiratory failure ${ }^{c}$} \\
\hline no & & 47 & 52.8 & 70 & 52.6 & 22 & 55 & \multirow{4}{*}{0.95} & 139 & 53.1 \\
\hline yes & 1 & 33 & 37.1 & 36 & 27.1 & 9 & 22.5 & & 78 & 29.8 \\
\hline & $\geq 2$ & 7 & 7.9 & 25 & 18.8 & 8 & 20 & & 40 & 15.3 \\
\hline & Subtotal yes ${ }^{e}$ & 40 & 44.9 & 61 & 45.9 & 17 & 42.5 & & 118 & 45.0 \\
\hline \multicolumn{11}{|c|}{ Hospitalizations with procedures } \\
\hline & MV & 21 & 23.6 & 54 & 40.6 & 12 & 30.0 & 0.03 & 87 & 33.2 \\
\hline & NIV & 7 & 7.9 & 21 & 15.8 & 1 & 2.5 & 0.03 & 29 & 11.1 \\
\hline & Tracheostomy & 14 & 15.7 & 37 & 27.8 & 9 & 22.5 & 0.11 & 60 & 22.9 \\
\hline & PEG & 33 & 37.1 & 22 & 16.5 & 9 & 22.5 & 0.00 & 64 & 24.4 \\
\hline \multicolumn{11}{|c|}{ Vital status ${ }^{\dagger}$ and place of death } \\
\hline alive & & 8 & 9.0 & 37 & 27.8 & 3 & 7.5 & \multirow{4}{*}{0.35} & 48 & 18.3 \\
\hline dead & & 81 & 91.0 & 96 & 72.2 & 37 & 92.5 & & 214 & 81.7 \\
\hline & in hospital ${ }^{g}$ & 46 & 56.8 & 49 & 51.0 & 24 & 64.9 & & 114 & 53.3 \\
\hline & out of hospital ${ }^{9}$ & 35 & 43.2 & 47 & 48.9 & 13 & 35.1 & & 100 & 46.7 \\
\hline
\end{tabular}

${ }^{a}$ Chi square test $\mathrm{p}$ comparing proportions between patients with bulbar, spinal and unknown site of onset

${ }^{b}$ Excludes one patient who did not have any hospitalization after the diagnosis of ALS and four patients who died during the hospitalization in which the diagnosis of ALS was made

'At least one hospitalization after the diagnosis of ALS with discharge code for respiratory failure (ICD-9-CM codes 518.81, 518.82, 518.83, 518.84) in any position

${ }^{d}$ Subtotal of patients with at least one hospitalization with discharge code for respiratory failure

e Subtotal of patients with at least one hospitalization with discharge code for acute respiratory failure

Dead or alive at the end of follow up, December 31, 2011

9The denominator of percentages is the total number of deceased patients

Table 2 Number and distribution of the most common discharge diagnoses, by type of admission

\begin{tabular}{|c|c|c|c|c|c|c|c|c|c|c|c|c|c|c|c|c|}
\hline \multirow{4}{*}{ Discharge diagnosis (ICD-9-CM codes) } & \multicolumn{16}{|c|}{ Type of admission } \\
\hline & \multicolumn{4}{|c|}{$\begin{array}{l}\text { Emergency } \\
(N=421)\end{array}$} & \multicolumn{4}{|c|}{$\begin{array}{l}\text { Elective } \\
(N=299)\end{array}$} & \multicolumn{4}{|c|}{$\begin{array}{l}\text { Day hospital } \\
(N=165)\end{array}$} & \multicolumn{4}{|c|}{$\begin{array}{l}\text { Overall } \\
(N=885)\end{array}$} \\
\hline & \multicolumn{2}{|c|}{ Primary code ${ }^{a}$} & \multicolumn{2}{|c|}{ Any code ${ }^{b}$} & \multicolumn{2}{|c|}{ Primary code ${ }^{a}$} & \multicolumn{2}{|c|}{ Any code ${ }^{b}$} & \multicolumn{2}{|c|}{ Primary code ${ }^{a}$} & \multicolumn{2}{|c|}{ Any code ${ }^{b}$} & \multicolumn{2}{|c|}{ Primary code $\mathrm{a}^{\mathrm{a}}$} & \multicolumn{2}{|c|}{ Any code ${ }^{b}$} \\
\hline & $\bar{N}$ & (\%) & $\mathrm{N}$ & $\%$ & $\bar{N}$ & $\%$ & $\bar{N}$ & $\%$ & $\mathrm{~N}$ & $\%$ & $\mathrm{~N}$ & $\%$ & $\mathrm{~N}$ & $\%$ & $\mathrm{~N}$ & $\%$ \\
\hline ALS (335.20) & 112 & $(26.6)$ & 335 & $(79.6)$ & 154 & $(51.5)$ & 233 & $(77.9)$ & 122 & $(73.9)$ & 132 & $(80.0)$ & 388 & $(43.8)$ & 700 & $(79.1)$ \\
\hline Respiratory failure (518.81-.84) & 117 & (27.8) & 192 & (45.6) & 49 & $(16.4)$ & 79 & (26.4) & 6 & (3.6) & 9 & $(5.4)$ & 172 & $(19.4)$ & 280 & (31.6) \\
\hline Acute (518.81) & 93 & (22.1) & 138 & (32.8) & 44 & $(14.7)$ & 59 & $(19.7)$ & - & & 2 & $(1.2)$ & 137 & $(15.5)$ & 199 & $(22.5)$ \\
\hline Chronic (518.83) & 3 & $(0.7)$ & 9 & (2.1) & 2 & $(0.7)$ & 15 & $(5.0)$ & 6 & (3.6) & 6 & (3.6) & 11 & $(1.2)$ & 30 & $(3.4)$ \\
\hline Acute on chronic (518.84) & 12 & $(2.8)$ & 25 & (5.9) & 1 & $(0.3)$ & 2 & $(0.7)$ & - & & - & & 13 & $(1.5)$ & 27 & $(3.0)$ \\
\hline Unidentified (518.82) & 9 & $(2.1)$ & 21 & (5.0) & 2 & $(0.7)$ & 3 & $(1.0)$ & - & & 1 & $(0.6)$ & 11 & $(1.2)$ & 25 & $(2.8)$ \\
\hline Diseases of the respiratory system (460-519) & 71 & $(16.9)$ & 156 & $(37.0)$ & 7 & $(2.3)$ & 30 & $(10.0)$ & - & & 5 & $(3.0)$ & 78 & $(8.8)$ & 191 & $(21.6)$ \\
\hline Pneumonia and influenza (480-487) & 44 & $(10.4)$ & 105 & (24.9) & 5 & $(1.7)$ & 19 & $(6.3)$ & - & & 2 & $(1.2)$ & 49 & $(5.5)$ & 126 & $(14.2)$ \\
\hline Aspiration pneumonia (507.0) & 10 & (2.4) & 18 & $(4.3)$ & - & & 1 & $(0.3)$ & - & & - & & 10 & $(1.1)$ & 19 & $(2.1)$ \\
\hline
\end{tabular}

${ }^{a}$ Number and percentage (\%) of hospitalizations with the corresponding discharge diagnosis as primary code

${ }^{b}$ Number and percentage (\%) of hospitalizations with the corresponding discharge diagnosis as primary or any secondary code 
Table 3 Number and distribution of procedures, by type of admission

\begin{tabular}{|c|c|c|c|c|c|c|c|c|}
\hline \multirow[t]{3}{*}{ Procedures (ICD-9-CM codes) ${ }^{a}$} & \multicolumn{6}{|c|}{ Type of admission } & \multirow{2}{*}{\multicolumn{2}{|c|}{$\begin{array}{l}\text { Overall } \\
(N=885)\end{array}$}} \\
\hline & \multicolumn{2}{|c|}{$\begin{array}{l}\text { Emergency } \\
(N=421)\end{array}$} & \multicolumn{2}{|c|}{$\begin{array}{l}\text { Elective } \\
(N=299)\end{array}$} & \multicolumn{2}{|c|}{$\begin{array}{l}\text { Day hospital } \\
(N=165)\end{array}$} & & \\
\hline & $\bar{N}$ & $\%$ & $\bar{N}$ & $\%$ & $\overline{\mathrm{N}}$ & $\%$ & $\overline{\mathrm{N}}$ & $\%$ \\
\hline \multicolumn{9}{|l|}{ Respiratory function } \\
\hline Mechanical ventilation (96.7-96.72) & 126 & 29.9 & 37 & 12.4 & - & - & 163 & 18.4 \\
\hline$\geq 96 \mathrm{~h}(96.72)$ & 93 & 22.1 & 24 & 8.0 & - & - & 117 & 13.2 \\
\hline$<96$ h (96.71) & 17 & 4.0 & 4 & 1.3 & - & - & 21 & 2.3 \\
\hline Unspecified duration & 16 & 3.8 & 9 & 3.0 & - & - & 25 & 2.8 \\
\hline Tracheostomy (31.1-31.2) & 53 & 12.6 & 10 & 3.3 & - & - & 63 & 7.1 \\
\hline Non invasive ventilation (93.90) & 21 & 5.0 & 6 & 2.0 & 8 & 4.8 & 35 & 3.9 \\
\hline IPPB (93.91) & 6 & 1.4 & 7 & 2.3 & - & - & 13 & 1.5 \\
\hline Other respiratory therapy $(93.94,93.96,93.97,93.99)$ & 43 & 10.2 & 8 & 2.7 & - & - & 51 & 5.8 \\
\hline Measurement of arterial blood gases (89.65) & 79 & 18.8 & 40 & 13.3 & 7 & 4.2 & 126 & 14.2 \\
\hline \multicolumn{9}{|l|}{ Nutrition } \\
\hline Gastro- or entero- stomy & 40 & 9.5 & 39 & 13.0 & 7 & 4.2 & 86 & 9.7 \\
\hline $\mathrm{PEG}^{\mathrm{b}}(43.11)$ & 32 & 7.6 & 29 & 9.6 & 7 & 4.2 & 68 & 7.6 \\
\hline $\operatorname{PEJ}^{c}(46.32)$ & 5 & 1.1 & 6 & 2.0 & - & - & 11 & 1.2 \\
\hline Other gastrostomy (43.19) & 3 & 0.7 & 4 & 1.3 & - & - & 7 & 0.7 \\
\hline \multicolumn{9}{|l|}{ Diagnostic procedures } \\
\hline Electromyography (93.08) & 16 & 3.8 & 47 & 15.7 & 49 & 29.7 & 112 & 12.6 \\
\hline $\mathrm{MRI}^{\mathrm{d}}$ of brain, brain stem and spinal canal $(88.91,88.93)$ & 7 & 1.6 & 24 & 8.0 & 29 & 17.6 & 60 & 6.8 \\
\hline Spinal tap (03.31) & 4 & 0.9 & 10 & 3.3 & 5 & 3.0 & 19 & 2.1 \\
\hline Bronchoscopy (33.21) & 52 & 12.3 & 16 & 5.3 & 1 & 0.6 & 69 & 7.7 \\
\hline Open biopsy of soft tissue (83.21) & 1 & 0.2 & 14 & 4.6 & - & - & 15 & 1.6 \\
\hline
\end{tabular}

${ }^{a}$ ICD-9-CM codes for procedures in any position

${ }^{b}$ Percutaneous endoscopic gastrostomy

c Percutaneous endoscopic jejunostom

${ }^{d}$ Magnetic resonance imaging

were most common in day-hospital admissions (29.7 and $17.6 \%$, respectively).

The overall median survival of the entire cohort was 20.5 months (95 \% CI 17.2; 24.9) (Fig. 1). After the first hospitalization for respiratory failure, median survival time was 8.0 months $(95 \%$ CI $3.1 ; 13.2)$ and after the first hospitalization with MV 9.7 months (95 \% CI 4.1-18.2).

The first hospitalization with diagnosis of respiratory failure occurred on average 32.2 months (Standard Deviation SD 2.0; median 23.8 months) and with MV 21.0 months (SD 1.9; median 15.8 months) after the diagnosis (data not shown).

When simultaneously adjusting for site of onset, age and diagnostic delay, the first hospitalization for respiratory failure was associated with a fourfold increased risk of death (HR 4.00, 95 \% CI 3.00; 5.34) (Table 4). Adding a term for Charlson Index or hospitalizations before diagnosis (a total of 16 patients were hospitalized before diagnosis) did not change the results (Additional file 1: Table S2).

\section{Discussion}

In our population-based cohort, almost all ALS patients were hospitalized at least once and more than $75 \%$ twice or more. More than half of patients were hospitalized at least once for respiratory failure, mostly acute. Among all hospitalizations, respiratory failure was the leading discharge diagnosis, followed by other respiratory conditions and pneumonia including aspiration pneumonia. These results are consistent with those reported by two studies evaluating hospital admissions with a diagnostic code for ALS in US administrative databases [14, 15]. Respiratory failure and other respiratory conditions were more frequent in emergency than in elective admissions. Emergency admissions were common in patients with ALS: between 40 and $54 \%$ of patients were admitted through the emergency room $[14,15,23]$. 


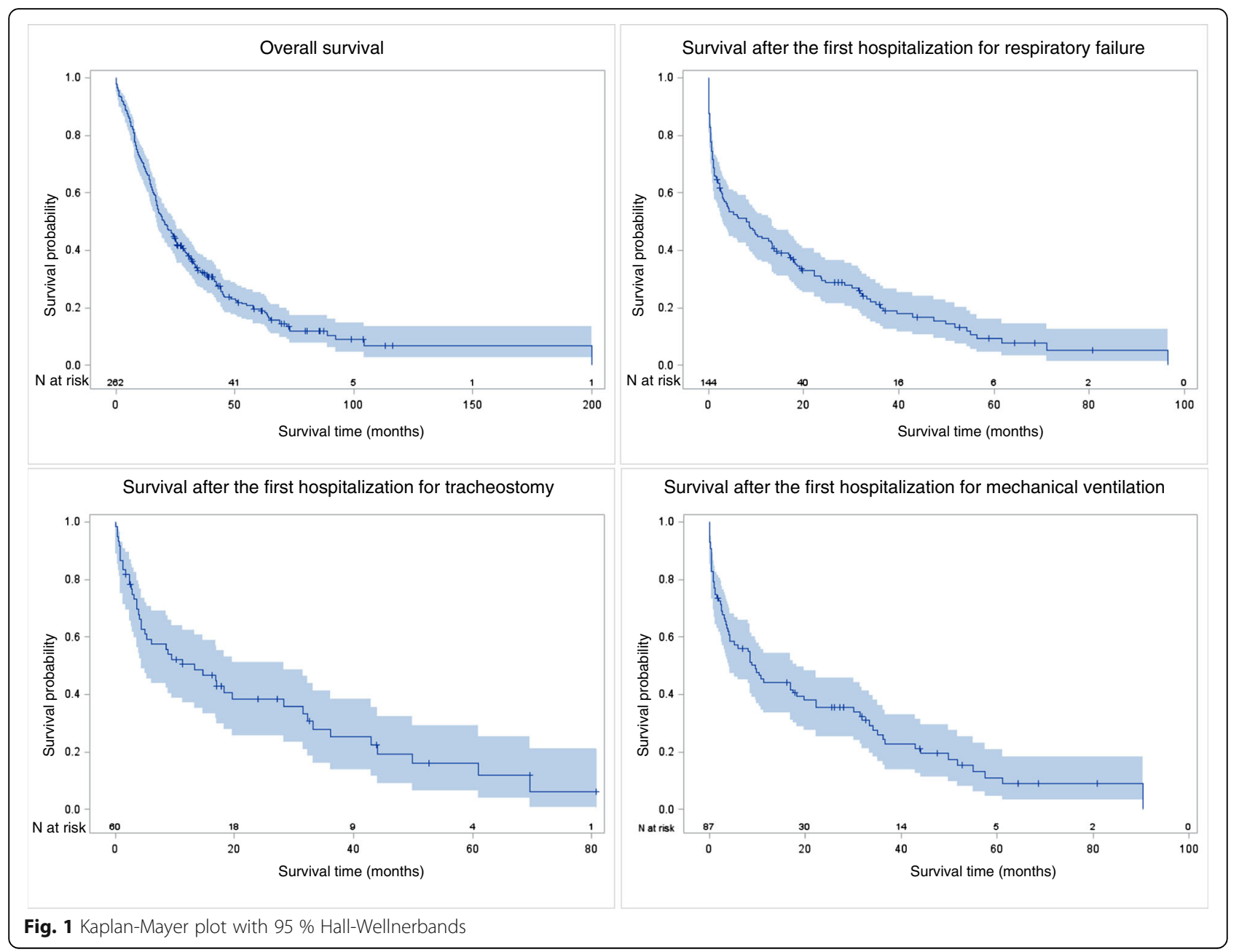

The leading procedures were those related to respiratory function, in particular MV was performed in one third of patients, and tracheostomy in more than $20 \%$, similarly to [11, 24] or higher than [10] other Italian studies. We do not have information to quantify the percentage of patients who refused tracheostomy or other procedures.

Only $11.1 \%$ of patients underwent NIV during an in-hospital stay. The prevalence of NIV was $47.7 \%$ in another Italian study collecting information from physicians providing patient care [11]. As hospital administrative data capture only in-hospital procedures, information on NIV performed out of hospital is lacking. Our results, therefore, do not represent the overall percentage of patients undergoing NIV but only those receiving it in-hospital. Patients with bulbar onset received NIV, MV and tracheostomy less frequently than those with spinal onset, consistently with other studies [11].

Tracheostomies, MV and in-hospital NIV were performed mostly in emergency non-programmed hospitalizations. Respiratory conditions were treated often in emergency admissions, contrary to recommendations $[5,6]$. This result may indicate poor planning of respiratory care and highlights an area for improvement of care of ALS patients. Consistently, in a recent study more than two-thirds of tracheostomies were placed in emergency [25].

Hospitalizations for respiratory failure increased the risk of in-hospital mortality from more than three-fold [15] to five-fold [14]. The longitudinal design of our study, with follow-up performed trough record-linkage with hospitalization and mortality records, allowed us to assess the impact of the first hospitalization for respiratory failure after the diagnosis of ALS on survival time and risk of death, including deaths occurred out of hospital after discharge. After the first hospitalization for respiratory failure, survival time was 8.0 months and after the first hospitalization with MV 9.7 months, shorter than in other population-based Italian studies, respectively of 19 months (95\% CI, 7-43) [11] and 21 months [10]. The first hospitalization for respiratory failure was a strong and independent negative prognostic factor. 
Table 4 Relation between mortality, hospitalizations for respiratory failure and clinical characteristics. Hazard Ratio (HR), with $95 \%$ Confidence Interval (95\% Cl)

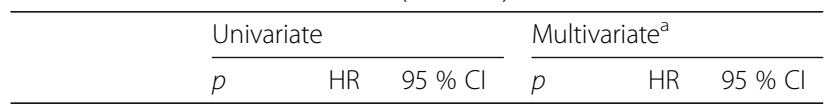

Hospitalization for respiratory failure

\begin{tabular}{|c|c|c|c|c|c|}
\hline $\mathrm{No}^{\mathrm{b}}$ & & 1.00 & - - & & 1.00 \\
\hline Yes & $<0.0001$ & 3.52 & $2.65 ; 4.67$ & $<0.0001$ & 4.00 \\
\hline
\end{tabular}

Site of onset

$\begin{array}{lllllll}\text { Spinal }^{\mathrm{b}} & & 1.00 & - & & 1.00 & - \\ \text { Bulbar } & 0.0005 & 1.71 & 1.27 ; 2.32 & 0.0791 & 1.32 & 0.97 ; 1.81\end{array}$

Missing $\quad 0.0084 \quad 1.69 \quad 1.14 ; 2.49 \quad 0.2113 \quad 1.31 \quad 0.86 ; 2.01$

Age (years)

$\begin{array}{llll}<68^{\mathrm{b}} & 1.00 & -- & 1.00\end{array}$

$\begin{array}{lllllll}\geq 68 & <0.0001 & 2.05 & 1.56 ; 2.69 & <0.0001 & 2.50 & 1.86 ; 3.36\end{array}$

Diagnostic delay

$\begin{array}{llllll}\geq \text { median }^{\mathrm{b}, \mathrm{c}} & 1.00 & - & - & 1.00 & - \text { - }\end{array}$

$\begin{array}{lllllll}\text { median }^{c} & 0.0065 & 1.81 & 1.18 ; 2.77 & 0.0004 & 2.23 & 1.43 ; 3.47\end{array}$

$\begin{array}{llllllll}\text { Unknown } & 0.1095 & 1.34 & 0.94 ; 1.91 & 0.0459 & 1.48 & 1.01 ; 2.19\end{array}$

${ }^{a}$ site of onset, age, diagnostic delay

${ }^{b}$ Reference category

c Median: 276 days

The median duration of hospital stay was 8 days, in line with the results of a prior Italian study (mean 10.3 days) [26] but longer than in a French study (mean 3.3 days) [13]. In the USA, the mean length of stay varied from 8.4 days [15] to 5 days [14].

Consistently with our results, in-hospital mortality was not associated with Charlson comorbidity score [14, 15]. In our study, a score $\geq 3$ appeared protective. Our results did not vary substantially when the term for Charlson Index score was removed from the model. The Charlson Index assigns the highest weights to conditions such as malignancies, diabetes with organ damage or moderate to severe renal disease, and may not capture clinical conditions that specifically influence the risk of death in patients with ALS, such as malnutrition [27] or respiratory problems. Comorbidities such as coronary heart disease, history of myocardial infarction, diabetes mellitus, seem to have no effect on the survival of ALS patients [28]. Moreover, these patients had less cardiovascular comorbidity and risk factors compared to the general population [28-30].

Nutritional deficiency occurred only in a small percentage of hospitalizations, contrary to other studies $[14,15]$. Nutritional procedures and gastro-enterostomies were performed mostly during elective hospitalizations. Diagnostic procedures were most common in day-hospital admissions. These findings suggest that the diagnostic pathway as well as nutritional support were well planned.
In our study, more than half of deceased patients died in hospital. This high percentage calls for improved advance terminal care planning.

In the region FVG, patients with ALS are offered clinical follow-up at the two University Hospitals of the Region. They are referred to outpatient respiratory clinics for assessment and follow-up of respiratory conditions. At the time of the study conduct, however, there was no common regional guideline for respiratory follow-up and home care nor for timing of initiation and methods of ventilation. Therefore, the follow-up of ALS patients was probably not uniform.

Integrated health care provision, including follow-up and home care of respiratory problems, has improved patients' quality of life and optimized hospital utilization, reducing emergency admissions [13, 17]. Our study therefore highlighted important areas of improvement in supportive care of patients with ALS.

\section{Strengths}

The main strength of our study is its population-based and longitudinal design.

This cohort included all incident cases in a welldefined time period and geographical area. The ascertainment of cases was complete, as suggested by incidence rates within the range of other European registries [19]. All study subjects were confirmed incident cases of ALS. Diagnosis was made according to consensus criteria and validated by an expert neurologist.

The probability of emergency gastrostomies varied according to ethnicity and health insurance of patients [25]. Our study was conducted in a universal health care system. All members of the cohort are residents of FVG and have the same criteria for access to hospital care, irrespectively of socio-economical status. The results are therefore not influenced by differential access to hospital care.

Hospitalization episodes were obtained from health administrative databases, an objective source. All episodes were captured, as the database records all hospitalizations occurred in public and private hospitals of FVG and of other Italian regions.

\section{Limitations}

Factors such as living without a partner [31], area of residency [32], nutritional status at diagnosis or during the course of disease [33] as well as a diagnosis of frontotemporal dementia [31], have an unfavorable prognostic role in ALS. Information on clinical, psychosocial or environmental factors were not recorded in our data and we could not assess their role.

As we lack information on preferences of patients and families, the percentage of patients offered NIV/MV in 
advance and the percentage of those who accepted could not be calculated.

\section{Conclusions}

In this population-based cohort of patients with ALS, hospitalizations were very common. Respiratory failure, pneumonia and aspiration pneumonia were the leading causes for hospital care utilization. Respiratory conditions were often dealt with in emergency admissions. Hospitalizations for respiratory failure had a strong independent negative effect on survival.

This study identified important areas for improvement in the care of patients with ALS. Strategies such as community-based interventions and care may improve the management of respiratory problems and reduce unnecessary emergency admissions. Improved advance terminal care planning may reduce the percentage of inhospital deaths.

More research is needed to assess the relation between patients' characteristics, such as socio-demographic factors, presence of support or area of residency, and hospital care utilization. Such studies could identify key factors in designing and implementing interventions aimed at improving the management of respiratory conditions in patients with ALS.

\section{Additional file}

Additional file 1: Table S1. Number and distribution of discharge diagnoses by type of admission, in hospitalizations ending with death. Table S2. Relation between mortality, hospitalizations for respiratory failure and clinical characteristics. Hazard Ratio (HR), with $95 \%$ Confidence Interval (95\% Cl). (DOCX $30 \mathrm{~kb}$ )

\section{Abbreviations}

ALS: Amyotrophic Lateral Sclerosis; BiPAP: Bilevel Positive Airway Pressure; CPAP: Continuous Positive Airway Pressure; FVG: Friuli Venezia Giulia; ICD-9CM: International Classification of Diseases ninth revision clinical modification; MRI: Magnetic resonance imaging; MV: Mechanical ventilation; NIV: Non invasive ventilation

\section{Acknowledgements}

The work was conducted at the Institute of Hygiene and Clinical Epidemiology, University Hospital of Udine, Udine, Italy.

\section{Funding}

This study was carried out by University of Udine with no external funding.

\section{Availability of data and materials}

Data are owned by the Region Friuli Venezia Giulia and cannot be shared.

\section{Authors' contributions}

FEP conception of research project, study design, study organization and execution, statistical analysis, manuscript writing, review and critique; GL study design, critical review of the manuscript; PGB data management, critical review of the manuscript; FB critical review of the manuscript. All authors read and approved the final manuscript.

\section{Authors' information}

None.

\section{Competing interests}

The authors declare that they have no competing interests.

Consent for publication

Not applicable.

\section{Ethics approval and consent to participate}

The Ethics Committee at the University Hospital of Udine reviewed and approved the study protocol. This was a retrospective study based on anonymized secondary data. At the point of care, all patients in FVG hospitals are requested to provide consent to the use of anonymized secondary data generated during the process of care for research purposes. Further consent to participate is waived.

\section{Author details}

${ }^{1}$ Institute of Hygiene and Clinical Epidemiology, University Hospital of Udine, Via Colugna 50, Udine 33100, Italy. ${ }^{2}$ Neurodegenerative Diseases Unit, Department of Basic Medicine Neuroscience and Sense Organs, Department of Clinical Research in Neurology of the University of Bari at "Pia Fondazione Card G.Panico" Hospital Tricase, Lecce, University of Bari, Bari, Italy.

${ }^{3}$ Department of Biological and Medical Sciences, University of Udine, Udine, Italy. ${ }^{4}$ Department of Medical Sciences, University of Trieste, Trieste, Italy.

Received: 4 January 2016 Accepted: 20 October 2016

Published online: 03 November 2016

\section{References}

1. Marin B, Logroscino G, Boumediene F, Labrunie A, Couratier P, Babron MC, Leutenegger AL, Preux PM, Beghi E. Clinical and demographic factors and outcome of amyotrophic lateral sclerosis in relation to population ancestral origin. Eur J Epidemiol. 2016;31(3):229-45. doi: 10.1007/s10654-015-0090-x. Epub 2015 Oct 12

2. Chio A, Logroscino G, Hardiman O, Swingler R, Mitchell D, Beghi E, Traynor BG. Prognostic factors in ALS: A critical review. Amyotroph Lateral Scler. 2009;10(5-6):310-23.

3. Capozzo R, Quaranta VN, Pellegrini F, Fontana A, Copetti M, Carratu P, Panza F, Cassano A, Falcone VA, Tortelli R, et al. Sniff nasal inspiratory pressure as a prognostic factor of tracheostomy or death in amyotrophic lateral sclerosis. J Neurol. 2015;262(3):593-603. doi:10.1007/s00415-014-7613-3. Epub 2014 Dec 19.

4. Pena MJ, Ravasco P, Machado M, Pinto A, Pinto S, Rocha L, de Carvalho M, Pinto HC. What is the relevance of percutaneous endoscopic gastrostomy on the survival of patients with amyotrophic lateral sclerosis? Amyotroph Lateral Scler. 2012;13(6):550-4. doi:10.3109/17482968.2012.684215. Epub 2012 Jun 18.

5. Andersen PM, Abrahams S, Borasio GD, de Carvalho M, Chio A, Van Damme P, Hardiman O, Kollewe K, Morrison KE, Petri S, et al. EFNS guidelines on the clinical management of amyotrophic lateral sclerosis (MALS) - revised report of an EFNS task force. Eur J Neurol. 2012;19(3):360-75. doi:10.1111/j.1468-1331. 2011.03501.x. Epub 2011 Sep 14

6. Miller RG, Jackson CE, Kasarskis EJ, England JD, Forshew D, Johnston W, Kalra S, Katz JS, Mitsumoto H, Rosenfeld J, et al. Practice parameter update: the care of the patient with amyotrophic lateral sclerosis: drug, nutritional, and respiratory therapies (an evidence-based review): report of the Quality Standards Subcommittee of the American Academy of Neurology. Neurology. 2009;73(15):1218-26. doi:10.1212/WNL.0b013e3181bc0141.

7. Radunovic A, Annane D, Rafiq MK, Mustfa N. Mechanical ventilation for amyotrophic lateral sclerosis/motor neuron disease. Cochrane Database Syst Rev. 2013; (3):CD004427. doi:10.1002/14651858.CD14004427.pub3.

8. Veronese S, Valle A, Chio A, Calvo A, Oliver D. The last months of life of people with amyotrophic lateral sclerosis in mechanical invasive ventilation: a qualitative study. Amyotroph Lateral Scler Frontotemporal Degener. 2014;15(7-8):499-504. doi:10.3109/21678421.2014.913637. Epub 2014 May 27.

9. Rabkin J, Ogino M, Goetz R, McElhiney M, Hupf J, Heitzman D, HeimanPatterson T, Miller R, Katz J, Lomen-Hoerth C, et al. Japanese and American ALS patient preferences regarding TIV (tracheostomy with invasive ventilation): a cross-national survey. Amyotroph Lateral Scler Frontotemporal Degener. 2014;15(3-4):185-91. doi:10.3109/21678421.2014.896928. Epub 2014 Apr 10. 
10. Chio A, Calvo A, Ghiglione P, Mazzini L, Mutani R, Mora G. Tracheostomy in amyotrophic lateral sclerosis: a 10-year population-based study in Italy. J Neurol Neurosurg Psychiatry. 2010;81(10):1141-3. doi:10.1136/jnnp.2009. 175984. Epub 2010 Jul 26.

11. Fini N, Georgoulopoulou E, Vinceti M, Monelli M, Pinelli G, Vacondio P, Giovannini M, Dallari R, Marudi A, Mandrioli J. Noninvasive and invasive ventilation and enteral nutrition for ALS in Italy. Muscle Nerve. 2014;50(4):508-16. doi:10.1002/mus.24187. Epub 2014 Aug 5.

12. Obermann M, Lyon M. Financial cost of amyotrophic lateral sclerosis: a case study. Amyotroph Lateral Scler Frontotemporal Degener. 2015;16(1-2):54-7. doi:10.3109/21678421.2014.951946. Epub 2014 Sep 23.

13. Cordesse V, Sidorok F, Schimmel P, Holstein J, Meininger V. Coordinated care affects hospitalization and prognosis in amyotrophic lateral sclerosis: a cohort study. BMC Health Serv Res. 2015;15:134. doi:10.1186/s12913-0150810-7.

14. Dubinsky R, Chen J, Lai SM. Trends in hospital utilization and outcome for patients with ALS: analysis of a large U.S. cohort. Neurology. 2006;67(5):777-80.

15. Lechtzin N, Wiener CM, Clawson L, Chaudhry V, Diette GB. Hospitalization in amyotrophic lateral sclerosis: causes, costs, and outcomes. Neurology. 2001;56(6):753-7.

16. Durheim MT, Collard HR, Roberts RS, Brown KK, Flaherty KR, King Jr TE, Palmer SM, Raghu G, Snyder LD, Anstrom KJ, et al. Association of hospital admission and forced vital capacity endpoints with survival in patients with idiopathic pulmonary fibrosis: analysis of a pooled cohort from three clinical trials. Lancet Respir Med. 2015;3(5):388-96. doi:10.1016/S22132600(15)00093-4. Epub 2015 Apr 15.

17. Pinto A, Almeida JP, Pinto S, Pereira J, Oliveira AG, de Carvalho M. Home telemonitoring of non-invasive ventilation decreases healthcare utilisation in a prospective controlled trial of patients with amyotrophic lateral sclerosis. J Neurol Neurosurg Psychiatry. 2010;81(11):1238-42.

18. [Istituto Italiano di Statistica ISTAT (Italian Statistical Institute). http://www. istat.it/it/friuli-venezia-giulia/dati. Last accessed on 9 Jun 2015. In.

19. Drigo D, Verriello L, Clagnan E, Eleopra R, Pizzolato G, Bratina A, D'Amico D, Sartori A, Mase G, Simonetto M, et al. The incidence of amyotrophic lateral sclerosis in Friuli Venezia Giulia, Italy, from 2002 to 2009: a retrospective population-based study. Neuroepidemiology. 2013:41(1):54-61.

20. Brooks BR. El Escorial World Federation of Neurology criteria for the diagnosis of amyotrophic lateral sclerosis. Subcommittee on Motor Neuron Diseases/Amyotrophic Lateral Sclerosis of the World Federation of Neurology Research Group on Neuromuscular Diseases and the El Escorial "Clinical limits of amyotrophic lateral sclerosis" workshop contributors. J Neurol Sci. 1994;124(Suppl):96-107.

21. Brooks BR, Miller RG, Swash M, Munsat TL. El Escorial revisited: revised criteria for the diagnosis of amyotrophic lateral sclerosis. Amyotroph Lateral Scler Other Motor Neuron Disord. 2000;1(5):293-9.

22. Powell TM BM. Your "Survival" Guide to Using Time Dependent Covariates. http://support.sas.com/resources/papers/proceedings12/168-2012.pdf. Last accessed on 30 Apr 2015. In.

23. Albert SM, Whitaker A, Rabkin JG, del Bene M, Tider T, O'Sullivan I, Mitsumoto H. Medical and supportive care among people with ALS in the months before death or tracheostomy. J Pain Symptom Manag. 2009;38(4): 546-53. doi:10.1016/j.jpainsymman.2008.11.013. Epub 2009 Jun 18.

24. Spataro R, Bono V, Marchese S, La Bella V. Tracheostomy mechanical ventilation in patients with amyotrophic lateral sclerosis: clinical features and survival analysis. J Neurol Sci. 2012;323(1-2):66-70. doi:10.1016/j.jns. 2012.08.011. Epub 2012 Sep 16.

25. Tsou AY, Karlawish J, McCluskey L, Xie SX, Long JA. Predictors of emergent feeding tubes and tracheostomies in amyotrophic lateral sclerosis (ALS). Amyotroph Lateral Scler. 2012;13(3):318-25. doi:10.3109/17482968.2012. 662987.

26. Chio A, Bottacchi E, Buffa C, Mutani R, Mora G. Positive effects of tertiary centres for amyotrophic lateral sclerosis on outcome and use of hospital facilities. J Neurol Neurosurg Psychiatry. 2006;77(8):948-50.

27. Desport JC, Marin B, Funalot B, Preux PM, Couratier P. Phase angle is a prognostic factor for survival in amyotrophic lateral sclerosis. Amyotroph Lateral Scler. 2008;9(5):273-8. doi:10.1080/17482960801925039.

28. Korner S, Kollewe K, Ilsemann J, Muller-Heine A, Dengler R, Krampfl K, Petri S. Prevalence and prognostic impact of comorbidities in amyotrophic lateral sclerosis. Eur J Neurol. 2013;20(4):647-54. doi:10.1111/ene.12015. Epub 2012 Oct 25.
29. Sutedja NA, van der Schouw YT, Fischer K, Sizoo EM, Huisman MH, Veldink JH, Van den Berg LH. Beneficial vascular risk profile is associated with amyotrophic lateral sclerosis. J Neurol Neurosurg Psychiatry. 2011:82(6):638-42. doi:10.1136/jnnp.2010.236752. Epub 2011 Apr 6.

30. Turner MR, Wotton C, Talbot K, Goldacre MJ. Cardiovascular fitness as a risk factor for amyotrophic lateral sclerosis: indirect evidence from record linkage study. J Neurol Neurosurg Psychiatry. 2012;83(4):395-8. doi:10.1136/ jnnp-2011-301161. Epub 2011 Nov 9.

31. Wolf J, Safer A, Wohrle JC, Palm F, Nix WA, Maschke M, Grau AJ. Factors Predicting Survival in ALS Patients-Data from a Population-Based Registry in Rhineland-Palatinate, Germany. Neuroepidemiology. 2015:44(3):149-55. doi:10.1159/000381625. Epub 2015 Apr 21

32. Keren N, Scott KM, Tsuda M, Barnwell J, Knibb JA, Ellis CM, Leigh PN, Shaw CE, Al-Chalabi A. Evidence of an environmental effect on survival in ALS. Amyotroph Lateral Scler Frontotemporal Degener. 2014;15(7-8): 528-33. doi:10.3109/21678421.2014.911326. Epub 2014 May 27.

33. Marin B, Desport JC, Kajeu P, Jesus P, Nicolaud B, Nicol M, Preux PM, Couratier P. Alteration of nutritional status at diagnosis is a prognostic factor for survival of amyotrophic lateral sclerosis patients. J Neurol Neurosurg Psychiatry. 2011;82(6):628-34. doi:10.1136/jnnp.2010.211474. Epub 2010 Nov 19

\section{Submit your next manuscript to BioMed Central and we will help you at every step:}

- We accept pre-submission inquiries

- Our selector tool helps you to find the most relevant journal

- We provide round the clock customer support

- Convenient online submission

- Thorough peer review

- Inclusion in PubMed and all major indexing services

- Maximum visibility for your research

Submit your manuscript at www.biomedcentral.com/submit
) Biomed Central 